\title{
Approaching Collaborative Flow in Collaborative Gaming, a Survey Study
}

\author{
Jaakko Ohrankämmen, Paula Alavesa, Leena Arhippainen \\ University of Oulu \\ Oulu, Finland \\ jaakko.ohrankammen, paula.alavesa, leena.arhippainen@oulu.fi
}

\begin{abstract}
Flow is an aspect of player experience that has been often targeted in game studies. Still, similar to presence it can be ambiguous and difficult to quantify. In this study, we approach the concept of flow in cooperative gaming and frame the target of this study as "collaborative flow". Team-play and Flow relevant aspects of player experience, Flow, Co-presence, Sensory Immersion, Imaginative Immersion, Behavioral involvement, Social Presence, and Engagement, were mapped in an online survey with 75 participants. We noticed small significant differences between semi-professional gamers and hobbyists in some flow related aspects of player experience. In addition, weekly gaming time influenced the results. In this study we used existing validated questionnaires and can only state that better metrics and definitions for this aspect of player experience are needed for future research.
\end{abstract}

\section{INTRODUCTION}

Flow is considered a positive deep state of consciousness experienced when people engage in tasks [1], [2]. It is also possible in many situations for people to have joined sensation of flow, described as group flow [3] or team cognition [4]. Collaboration and cooperation are a key in team esports. While esports encompasses many genres, and both individual and team performances, it is considered a competitive sports, where performance is a key. The interest of research on the topic and knowledge on the psychological factors in esports has increased over the past decades [5], [6]. Esports research has evolved from trying to explain the phenomena to audiences to describing the complex mechanics that make esports what it is. Many fields study esports from different perspectives [6]. Some approaches are heavily influenced by methods used in traditional sports. While the recreational gaming has shifted to professional domain, there is still a connection. The same video games that are played in esports are still played by gamers of all levels [5]-[7]. Walker's studied sense of enjoyment comparing social and solo flow in a controlled setting while conducting tasks [8]. In his study Walker observed that people enjoy social flow more. It is also well known that people tend to enjoy social aspects of gameplay and find them highly motivating [9], [10].

Much of attention in esports research is on improving performance from the perspective of psychology. Attention is placed to aspects of cognitive performance [11]. In this study we used a psychometric questionnaires used in game user research. The aspects chosen for for mapping were: Co-presence [12], Flow, Sensory and imaginative immersion,
Behavioral involvement, social presence [13], [14], Cognitive engagement (Conscious Attention \& Absorption) and Behavioral engagement (Social connectedness \& Interaction) [15], [16]. The survey was answered by 75 participants. The goal of our study is to explore how solo, collaborative and avid gamers perceive flow and flow related aspects of player experience. We hope our findings have relevance for esports and possibly any human endeavours that require joined action that is mediated by digital media.

\section{RELATED WORK}

\section{A. Flow}

Flow is defined by Csikszentmihalyi [1], [2] as a deep state of consciousness people feel, while focusing on tasks. According to Csikszentmihalyi's definition of Flow experience it is an optimal experience, where a user is completely focused on own task and forgot all surroundings. It has been unequivocally described as a positive rewarding experience. The original description of flow was based on observation creative processes but since then the sense of flow has been observed in a wide variety of different contexts including digital gaming and esports [17]-[19].

\section{B. Collaborative flow}

While flow can be categorized as a habitual state of deep concentration, the people experiencing it are not asleep. They are operating, playing or interacting, which allows us to consider outside influences to this experience, even social aspects. In this study we call this experience collaborative flow, a state of mind where emergent coordinated action [20], [21] enhances the flow experience. Takalo et al. [19] describe an optimal state of flow as emergent of an "ideal situation, where skills and challenges are high and in balance". We propose adding joined action to the "skills and challenges" to find optimal collaborative flow. Freeman and Wohn [22] and Lipovaya et al. [4] note that in some situations the team's performance is so high that players start to accurately predict actions of their fellow players. This results in on extremely fine-tuned teamwork called team cognition by [22]. Kaye [3] calls this collaborative flow "group flow" due to the how differently flow is perceived by solo and cooperative gamers. Solo players experienced stronger flow probed using the psychometric questionnaire Flow State Scale-Short Form [23], [24]. 


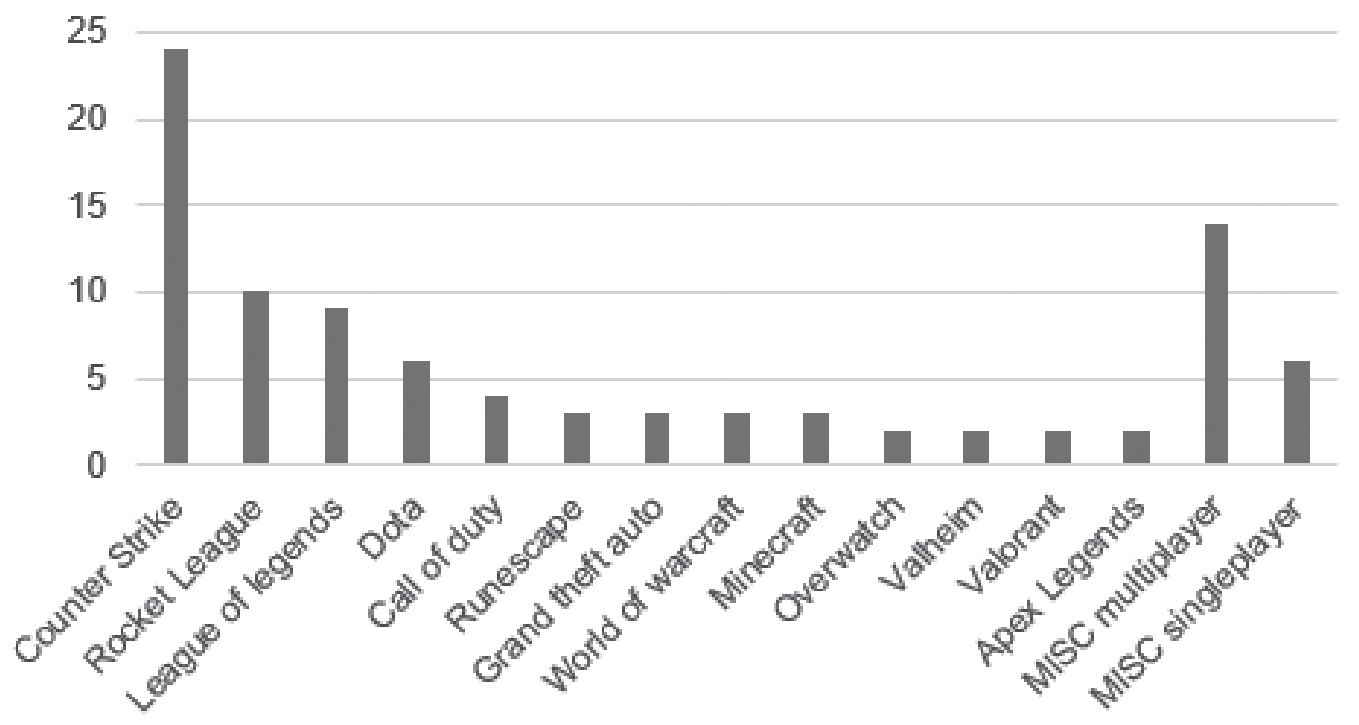

Fig. 1. The games survey participants reported playing. Miscellaneous (MISC) multiplayer and MISC singleplayer are collections of answers that got only single reply

\section{Evaluating flow with psychometric questionnaires}

Aspects of player experience are overlapping and interconnected. Poels et al. [25] characterize, as one subcomponent of player experience, flow divided into concentration and absorption. Sweetser and Wyeth [26] describe more broadly game flow, an experience that is comprised of concentration, challenge, skills, control, clear goals, feedback, immersion, and social interaction. In other words, they sum up game flow as a collection of many positive rewarding aspects of player experience. In this study we chose to map Co-presence [12], Flow, Sensory and imaginative immersion, Behavioral involvement, social presence [13], [14], Cognitive engagement (Conscious Attention \& Absorption) and Behavioral engagement (Social connectedness \& Interaction) [15], [16]. Our goal was to explore the aspects of player experience that influence or might result into emergence of collaborative flow with avid gamers.

\section{METHOD AND MATERIALS}

This paper presents findings from an online survey that was distributed via Discord and University of Oulu, Finland, mailing lists. 75 participants responded to the survey during April 5th- May 14th 2021.

\section{A. Participants}

The survey respondents were aged between 14-56 (M=24.2, $S D=5.5)$. The gender distribution of the respondents was uneven, with only 8 female respondent, 66 male and one undisclosed. The gender enquiry was open to other than binary answers. For dividing the players to three groups based on their weekly hours played, we used the categorization by Hussain and Griffiths [27] that divides gamers based on the hours played into three groups casual (0-15 h/week), regular (15$30 \mathrm{~h} /$ week) and excessive (>30 h/week) gamers. The survey participants were not subjected to the names of the categories as we though it might influence how they answer. Eight participants reported being semi-professional gamers while the rest reported the gaming to be a hobby. The participants had gaming experience between 1-31 years $(\mathrm{M}=15.2, S D=5.9)$. The highest variance amongst players was in the games they reported playing (Fig. 1)

\section{B. Survey structure}

The survey for player experience consisted of 52 statements derived of three individual questionnaires. English versions of the questionnaires were used. Short co-presence questionnaire by [12], game experience questionnaire (GEQ) [13], [14] and a more recent questionnaire the consumer videogame engagement scale (CVES) by Abbasi et al. [15], [16]. Categories perceived relevant to the concept of collaborative flow were chosen. The full list of questionnaire items is as follows:

- Co-presence [12]

- Flow [13], [14]

- Sensory and Imaginative Immersion [13], [14]

- Social Presence: Behavioral Involvement [13], [14]

- Social Presence: Psychological Involvement empathy [13], [14]

- Social Presence: Psychological Involvement negative feelings [13], [14]

- Cognitive Engagement: Conscious Attention [15], [16]

- Cognitive Engagement: Absorption [15], [16]

- Behavioral Engagement: Social Connectedness [15], [16]

- Behavioral Engagement: Interaction [15], [16]

The item "Behavioral Engagement: Interaction" specifically refers to social interaction according to the original source [15], [16], despite the formal name of the questionnaire item. The survey also informed the respondents that the collected 
TABLE I. STATISTICALLY SIGNIFICANT RESULTS FROM ONE WAY ANOVA COMPARING SOLO AND TEAM PLAYERS

\begin{tabular}{|c|c|c|c|c|c|c|c|}
\hline & \multirow[t]{2}{*}{ Group } & \multirow[t]{2}{*}{$\mathbf{N}$} & \multirow[t]{2}{*}{ Mean } & \multirow[t]{2}{*}{$\begin{array}{c}\text { Std. } \\
\text { Deviation }\end{array}$} & \multicolumn{2}{|c|}{$\begin{array}{l}95 \% \text { Confidence } \\
\text { Interval for Mean }\end{array}$} & \multirow[t]{2}{*}{ p-value } \\
\hline & & & & & $\begin{array}{l}\text { Lower } \\
\text { Bound }\end{array}$ & $\begin{array}{l}\text { Upper } \\
\text { Bound }\end{array}$ & \\
\hline \multirow[t]{2}{*}{ Co-presence } & Alone & 72 & 4,32 & 2,135 & 3,82 & 4.82 & \multirow[t]{2}{*}{$<0.001$} \\
\hline & Team & 215 & 5,33 & 1,390 & 5,14 & 5.52 & \\
\hline \multirow[t]{2}{*}{$\begin{array}{l}\text { Social Presence: Behavioral } \\
\text { Involvement (GEQ) }\end{array}$} & Alone & 126 & 5,13 & 1,743 & 4,82 & 5.43 & \multirow[t]{2}{*}{0.001} \\
\hline & Team & 324 & 5,65 & 1,335 & 5,50 & 5.79 & \\
\hline \multirow[t]{2}{*}{$\begin{array}{l}\text { Social Presence: Psychological } \\
\text { Involvement Empathy (GEQ) }\end{array}$} & Alone & 126 & 3,99 & 1,887 & 3,66 & 4.32 & \multirow[t]{2}{*}{$<0.001$} \\
\hline & Team & 324 & 5,32 & 1,449 & 5,16 & 5.48 & \\
\hline \multirow[t]{2}{*}{$\begin{array}{c}\text { Social Presence: Psychological } \\
\text { Involvement Negative Feelings (GEQ) }\end{array}$} & Alone & 105 & 3,56 & 1,941 & 3,19 & 3.94 & \multirow[t]{2}{*}{0.005} \\
\hline & Team & 270 & 4,20 & 1,954 & 3,96 & 4,43 & \\
\hline \multirow[t]{2}{*}{$\begin{array}{l}\text { Behavioural Engagement: } \\
\text { Social Connection (CVES) }\end{array}$} & Alone & 63 & 5,63 & 1,506 & 5,26 & 6,01 & \multirow[t]{2}{*}{0.009} \\
\hline & Team & 162 & 6,17 & 1,291 & 5,97 & 6,37 & \\
\hline \multirow[t]{2}{*}{$\begin{array}{l}\text { Behavioural Engagement: } \\
\text { Interaction (CVES) }\end{array}$} & Alone & 105 & 4,56 & 1,966 & 4,18 & 4,94 & \multirow[t]{2}{*}{0.004} \\
\hline & Team & 270 & 5,13 & 1,623 & 4,94 & 5,32 & \\
\hline
\end{tabular}

material would be used for research purposes. All material was collected anonymously.

\section{Results and analysis}

The tool for statistical analysis was SPSS Statistics 27 [28]. OneWay ANOVA was conducted for comparisons.

1) Solo and team players: As expected there were statistically significant difference between those who played solo (21 participants) and in a team (54 participants) differed Copresence, Social Presence: Behavioural Involvement, Social Presence: Psychological Involvement (empathy \& negative feelings), Social Connectedness and Interaction (Table I). None of the other aspects of player experience produced statistically significant results.

2) Influence of team size: Since we also enquired the team size from the participants we separated those who play solo (21), and teams of 2-3 (17 participants) or >3 (36). Three values were missing from the team size. In the group of $>3$ the mean group size was 5.0 with $\mathrm{SD}=0.8$. The most played game of each participant would have effected the team size. The most common team size for those who mainly played Counter Strike was 5. One MISC multiplayer (Fig. 1) gamer gave the value of 40, guild size perhaps, despite reporting being a solo player. We had two participants who reported mainly playing solo, but in addition having a team of two players. For this comparison, they were kept in the sologroup based on their main game style. There were not enough participants to compare reported team sized individually and gain significant results. Just as with comparison of solo and team players there were significant results in all social player experience measuring items in the questionnaire: Co-presence, Social Presence: Behavioural Involvement, Social Presence: Psychological Involvement (empathy \& negative feelings), Social Connectedness and Interaction. In addition, Sensory and Imaginative Immersion (GEQ) yielded statistically significant results (Table II).
3) Influence of game time: We also observed some influence on weekly game time on player experience (Table III). Social Presence: Psychological Involvement Empathy was higher with participants playing 0-30h weekly, making them either casual or regular gamers according to [27]. We also noticed quite low p-values $(0.060$ and 0.061$)$ on two other items: Sensory and Imaginative Immersion (GEQ) and Cognitive Engagement: Conscious Attention (CVES). Suggesting higher immersion with casual and regular gamers, but slightly higher conscious attention amongst regular and excessive gamers.

4) Observations on avid gamers: We had only eight semiprofessional gamers in our sample. They were all regular or excessive players. Comparing this small number of players to the others yielded statistically significant results (Table IV) in Social Presence Behavioural Involvement (GEQ), Cognitive Engagement: Conscious Attention (CVES) and Behavioural Engagement: Interaction (CVES). All of these were higher amongst the semi-professional gamers.

Based on our study setup and survey findings different aspects of player experience are influenced by four factors: Solo or team play, Team size, Game time and Player dedication (Fig. 2). Solo play has different dynamics than team play hence it has been separated from Team size. Similarly, Player dedication and Game time are connected however our results show that more professional players and hobbyists experience different aspects of collaborative flow very differently, therefor these influences need to be presented and studied separately.

\section{DISCUSSION}

In this study we began approaching collaborative flow amongst gamers. However, our findings show that while social aspects of gameplay can be measured using the co-presence questionnaire by [12], GEQ [13], [14] and CVES [15], [16], we need better metrics to approach flow related aspects of solo and team gaming. In addition, metrics or other methods are needed for observing collaborative flow. Our findings 
TABLE II. STATISTICALLY SIGNIFICANT RESULTS FROM ONE WAY ANOVA COMPARING SOLO AND TEAM PLAYERS WITH TEAM SIZE 1-3 AND ABOVE 3

\begin{tabular}{|c|c|c|c|c|c|c|c|}
\hline & \multirow[t]{2}{*}{ Group } & \multirow[t]{2}{*}{$\mathbf{N}$} & \multirow[t]{2}{*}{ Mean } & \multirow[t]{2}{*}{$\begin{array}{c}\text { Std. } \\
\text { Deviation }\end{array}$} & \multicolumn{2}{|c|}{$\begin{array}{l}\text { 95\% Confidence } \\
\text { Interval for Mean }\end{array}$} & \multirow[t]{2}{*}{ p-value } \\
\hline & & & & & $\begin{array}{l}\text { Lower } \\
\text { Bound }\end{array}$ & $\begin{array}{l}\text { Upper } \\
\text { Bound }\end{array}$ & \\
\hline \multirow[t]{3}{*}{ Co-presence } & Solo & 72 & 4.32 & 2.135 & 3.82 & 4.82 & \multirow[t]{3}{*}{$<0.001$} \\
\hline & $1-3$ & 68 & 5.40 & 1.508 & 5.03 & 5.76 & \\
\hline & $>3$ & 143 & 5.34 & 1.332 & 5.12 & 5.56 & \\
\hline \multirow{3}{*}{$\begin{array}{l}\text { Sensory and Imaginative } \\
\text { Immersion (GEQ) }\end{array}$} & Solo & 126 & 4.73 & 1.773 & 4.42 & 5.04 & \multirow[t]{3}{*}{0.049} \\
\hline & $1-3$ & 102 & 4.77 & 1.628 & 4.45 & 5.09 & \\
\hline & $>3$ & 216 & 4.34 & 1.818 & 4.09 & 4.58 & \\
\hline \multirow[t]{3}{*}{$\begin{array}{l}\text { Social Presence: Behavioral } \\
\text { Involvement (GEQ) }\end{array}$} & Solo & 126 & 5.13 & 1.743 & 4.82 & 5.43 & \multirow[t]{3}{*}{$<0.001$} \\
\hline & $1-3$ & 102 & 5.42 & 1.308 & 5.16 & 5.68 & \\
\hline & $>3$ & 216 & 5.79 & 1.337 & 5.61 & 5.97 & \\
\hline \multirow[t]{3}{*}{$\begin{array}{l}\text { Social Presence: Psychological } \\
\text { Involvement Empathy (GEQ) }\end{array}$} & Solo & 126 & 3.99 & 1.887 & 3.66 & 4.32 & \multirow[t]{3}{*}{$<0.001$} \\
\hline & $1-3$ & 102 & 5.57 & 1.278 & 5.32 & 5.82 & \\
\hline & $>3$ & 216 & 5.22 & 1.518 & 5.02 & 5.43 & \\
\hline \multirow[t]{3}{*}{$\begin{array}{c}\text { Social Presence: Psychological } \\
\text { Involvement Negative Feelings (GEQ) }\end{array}$} & Solo & 105 & 3.56 & 1.941 & 3.19 & 3.94 & \multirow[t]{3}{*}{0.005} \\
\hline & $1-3$ & 85 & 4.49 & 1.790 & 4.11 & 4.88 & \\
\hline & $>3$ & 180 & 4.06 & 2.024 & 3.76 & 4.35 & \\
\hline \multirow[t]{3}{*}{$\begin{array}{l}\text { Behavioural Engagement: } \\
\text { Social Connection (CVES) }\end{array}$} & Solo & 63 & 5.63 & 1.506 & 5.26 & 6.01 & \multirow[t]{3}{*}{0.005} \\
\hline & $1-3$ & 51 & 6,47 & 0.946 & 6.20 & 6.74 & \\
\hline & $>3$ & 108 & 6.06 & 1.413 & 5.79 & 6.33 & \\
\hline \multirow[t]{3}{*}{$\begin{array}{l}\text { Behavioural Engagement: } \\
\text { Interaction (CVES) }\end{array}$} & Solo & 105 & 4.56 & 1.966 & 4.18 & 4.94 & \multirow[t]{3}{*}{0.016} \\
\hline & $1-3$ & 85 & 5.20 & 1.557 & 4.86 & 5.54 & \\
\hline & $>3$ & 180 & 5.11 & 1.670 & 4.86 & 5.35 & \\
\hline
\end{tabular}

TABLE III. GAME TIME AND ITS INFLUENCE ON PLAYER EXPERIENCE

\begin{tabular}{|c|c|c|c|c|c|c|c|}
\hline & \multirow[t]{2}{*}{$\begin{array}{l}\text { Game } \\
\text { time }\end{array}$} & \multirow[t]{2}{*}{$\mathbf{N}$} & \multirow[t]{2}{*}{ Mean } & \multirow[t]{2}{*}{$\begin{array}{c}\text { Std. } \\
\text { Deviation }\end{array}$} & \multicolumn{2}{|c|}{$\begin{array}{l}\text { 95\% Confidence } \\
\text { Interval for Mean }\end{array}$} & \multirow[t]{2}{*}{ p-value } \\
\hline & & & & & $\begin{array}{l}\text { Lower } \\
\text { Bound }\end{array}$ & $\begin{array}{l}\text { Upper } \\
\text { Bound }\end{array}$ & \\
\hline \multirow{3}{*}{$\begin{array}{l}\text { Sensory and Imaginative } \\
\text { Immersion (GEQ) }\end{array}$} & $0-15$ & 180 & 4.55 & 1.679 & 4.30 & 4.80 & \multirow[t]{3}{*}{0.060} \\
\hline & $15-30$ & 180 & 4.73 & 1.671 & 4.48 & 4.97 & \\
\hline & $>30$ & 90 & 4.19 & 2.044 & 3.76 & 4.62 & \\
\hline \multirow[t]{3}{*}{$\begin{array}{l}\text { Social Presence: Psychological } \\
\text { Involvement Empathy (GEQ) }\end{array}$} & $0-15$ & 180 & 5.16 & 1.616 & 4.92 & 5.39 & \multirow[t]{3}{*}{0,002} \\
\hline & $15-30$ & 180 & 5.02 & 1.519 & 4.79 & 5.24 & \\
\hline & $>30$ & 90 & 4.39 & 2.026 & 3.96 & 4.81 & \\
\hline \multirow[t]{3}{*}{$\begin{array}{c}\text { Gognitive Engagement: Consious } \\
\text { Attention (CVES) }\end{array}$} & $0-15$ & 180 & 4.76 & 1.652 & 4.52 & 5.00 & \multirow[t]{3}{*}{0.061} \\
\hline & $15-30$ & 180 & 5.18 & 1.641 & 4.94 & 5.42 & \\
\hline & $>30$ & 90 & 5.09 & 1,987 & 4.67 & 5.50 & \\
\hline
\end{tabular}

also show that semi-professional and hobbyists have differing experiences in aspects of player dedication (Fig. 2, Table IV). This suggests that separating esports player experience and player experience in general is needed for optimal research output and better coaching of athlete gamers.

We noticed some interesting differences in groups of players depending on team size and game time. Casual and regular gamers rated higher in Social Presence: Psychological Involvement Empathy than gamers who play over 30 hours a week. Although our sample of semi-professional gamers was small, when their player experience was compared with the hobbyists we noticed that they rated higher in two social player experi- ence items Social Presence Behavioural Involvement (GEQ), and Behavioural Engagement: Interaction (CVES). In addition, they rated higher in Cognitive Engagement: Conscious Attention (CVES). This is encouraging for future studies on player experience in competitive gaming and differs interestingly from the larger sample of players comparing the gamers who play below and over 30 hours a week. With that larger sample we had a low $\mathrm{p}$-value $(\mathrm{p}=0.061)$ on similar difference in Cognitive Engagement: Conscious Attention (CVES), but the negative effect on Social Presence: Psychological Involvement Empathy for those gaming $>30 \mathrm{~h}$ a week could not be repeated with the small group of semi-professionals. While the p-value 
TABLE IV. DIFFERENCES BETWEEN HOBBYISTS AND SEMI-PROFESSIONAL GAMERS

\begin{tabular}{|c|c|c|c|c|c|c|c|}
\hline & \multirow[t]{2}{*}{ Group } & \multirow[t]{2}{*}{$\mathbf{N}$} & \multirow[t]{2}{*}{ Mean } & \multirow[t]{2}{*}{$\begin{array}{c}\text { Std. } \\
\text { Deviation }\end{array}$} & \multicolumn{2}{|c|}{$\begin{array}{l}\text { 95\% Confidence } \\
\text { Interval for Mean }\end{array}$} & \multirow[t]{2}{*}{ p-value } \\
\hline & & & & & $\begin{array}{l}\text { Lower } \\
\text { Bound }\end{array}$ & $\begin{array}{l}\text { Upper } \\
\text { Bound }\end{array}$ & \\
\hline \multirow[t]{2}{*}{$\begin{array}{l}\text { Social Presence: Behavioral } \\
\text { Involvement (GEQ) }\end{array}$} & Hobby & 402 & 5,43 & 1,517 & 5,28 & 5,58 & \multirow[t]{2}{*}{0,003} \\
\hline & $\begin{array}{c}\text { Semi- } \\
\text { Professional }\end{array}$ & 48 & 6,10 & 0,905 & 5,84 & 6,37 & \\
\hline \multirow[t]{2}{*}{$\begin{array}{c}\text { Gognitive Engagement: } \\
\text { Conscious Attention (CVES) }\end{array}$} & Hobby & 402 & 4,93 & 1,705 & 4,76 & 5,09 & \multirow[t]{2}{*}{0,016} \\
\hline & $\begin{array}{c}\text { Semi- } \\
\text { Professional }\end{array}$ & 48 & 5,56 & 1,821 & 5,03 & 6,09 & \\
\hline \multirow[t]{2}{*}{$\begin{array}{l}\text { Behavioral Engagement: } \\
\text { Interaction (CVES) }\end{array}$} & Hobby & 335 & 4,89 & 1,761 & 4,70 & 5,08 & \multirow[t]{2}{*}{0,007} \\
\hline & $\begin{array}{c}\text { Semi- } \\
\text { Professional }\end{array}$ & 40 & 5,68 & 1,403 & 5,23 & 6,12 & \\
\hline
\end{tabular}

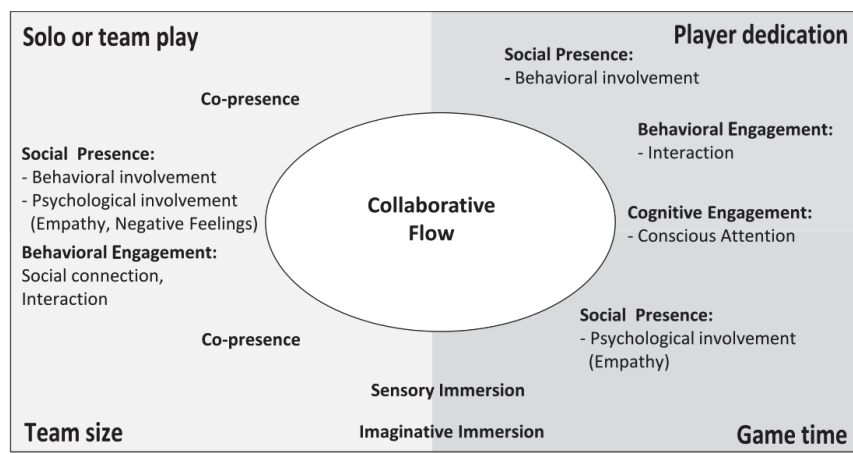

Fig. 2. Four influences on different aspects of player experience

escapes the $95 \%$ confidence interval, we chose report it in this paper due to the implications of the results.

\section{A. Future research paths}

Considering this is a survey study where we would have liked to observe gaming style specific statistical differences in results, the sample of 75 is still quite small. A bigger sample would have helped comparing team sizes and their influence on aspects of flow related player experience. We can easily speculate that there is a correlation with the game played and aspects of player experience, especially the social aspects, since the game played directly influences the number of people in a game team. The degree of cooperation does not just vary from solo to team-play but according to what game is being played. This is also perhaps the biggest limitation of our study. The amount of social interactions required for successful joined action is possibly also influence on the communication requirements and whether the players are colocated or teleconferencing. It would be certainly interesting to investigate how collaborative flow changes depending on this degree and level of cooperation. In other words, in the future we would like to continue our survey to see if a bigger sample would yield more statistically relevant results in the flow related aspects of game experience.
Based on our study we state that better metrics are needed to define collaborative flow and measure it. We would like to define these metrics for studying collaborative flow in gaming and esports, to learn more about its value for both casual gamers and for esports coaching. Better metrics would also allow better resolution when trying to observe differences between games and degree of required collaboration. In the future, we would also suggest looking into other popular ways of collecting data from gamers with biometrics [29] or game analytics [30] and using a more mixed method approach for defining and observing collaborative flow. Our goal is to define collaborative flow as a key aspect of player experience. Aubé, Rousseau and Brunelle [31] observed in their study on collaborative flow and the social hierarchies of teams that the best setup for collaborative flow is in teams with shared leadership. Looking into the hierarchies teams that play together frequently might also reveal interesting aspects on how collaborative flow emerges in teams that play together.

\section{B. Limitations}

In addition to the small sample size, our survey suffers from the same uncertainties as many survey studies. We encouraged the participants to answer the survey right after a normal gaming session, but we cannot verify this occurred. In addition, the participants have been playing in an uncontrolled environment various different games (Fig. 1).

In this study we have adopted the division used by Hussain and Griffiths [27] for dividing players into three groups based on the hours played: casual, regular and excessive gamers. While we adopted the use of the phrase excessive to those who play $>30 \mathrm{~h} /$ week, we do acknowledge that the word excessive is not suitable to describe the gaming habits of semiprofessional gamers to whom $>30 \mathrm{~h} /$ week might be normal weekly working/training hours.

Our sample has an obvious gender imbalance. There is a preconception that female gamers are casual gamers and male gamers more hard-core, we know that this is not true with casual gamers of whom the gender distribution is quite close to equal [32]. Amongst professional gamers this is to an extend true as most esports gamers and followers are male [33]. 
However, we believe the uneven gender division in this study is partly derived from our method of recruiting participants. In the future we would hope to use an extended version of this survey with a more diverse group of gamers. In addition, to targeting more professional and semi-professional gamers.

GEQ has received some critique [34], [35], however it is not unusual to critique a psychometric questionnaire that is so widely used. For this study it was chosen due to its reliability in studies to produce distinguishable results, we in addition complemented it with other questionnaires and did not use the specific factors mentioned by Johnson, Gardner and Perry [35].

\section{Conclusions}

Collaborative flow is a joined experience of flow distinguishable from flow experience in solo gameplay. We hope these results help not just avid gamers such as esports players to achieve optimal collaborative flow, but also hope that these results have some relevance to those who design computer mediated cooperative systems. In this study we tried to approach this aspect of gameplay trough a survey targeting flow related and social aspects of player experience. According to our findings unsurprisingly the solo players do fair lower in social aspects of gameplay that those who play in teams. We also noticed that those who play more than 30 hours a week fared lower in sensory and imaginative immersion. We in addition identified future research paths for collaborative flow in gameplay and esports.

As usual with psychometric questionnaires the observed differences are subtle and we warrant more studies in the future for exploring the collaborative flow with better metrics and more distinguishable results between different game genres, game specific communication requirements for cooperation and number of players in a team.

\section{ACKNOWLEDGMENT}

We would like to thank all who participated in the survey. The second author has, during this research, received funding from Business Finland funded project Reboot Finland IoT Factory 33/31/2018, supported by Academy of Finland 6Genesis Flagship (318927).

\section{REFERENCES}

[1] M. Csikszentmihalyi, Beyond boredom and anxiety. Jossey-Bass, 2000.

[2] M. Csikszentmihalyi, Finding flow. New York: Basic Books, 1997.

[3] L. K. Kaye, "Exploring flow experiences in cooperative digital gaming contexts," Computers in Human Behavior, vol. 55, p. 286-291, 2016.

[4] V. Lipovaya, Y. Lima, P. Grillo, C. E. Barbosa, J. M. de Souza, and F. J. d. C. M. Duarte, "Coordination, communication, and competition in esports: A comparative analysis of teams in two action games," in Proceedings of 16th European Conference on Computer-Supported Cooperative Work-Exploratory Papers. European Society for Socially Embedded Technologies (EUSSET), 2018.

[5] G. Freeman and D. Y. Wohn, "esports as an emerging research context at chi: Diverse perspectives on definitions," URL: https://dl.acm.org/doi/ abs/10.1145/3027063.3053158/, 2017, accessed 19.2.2021.

[6] J. G. Reitman, M. J. Anderson-Coto, M. Wu, J. S. Lee, and C. Steinkuehler, "Esports research: A literature review," Games and Culture, vol. 15, no. 1, pp. 32-50, 2020. [Online]. Available: https://doi.org/10.1177/1555412019840892
[7] I. Pedraza-Ramirez, L. Musculus, M. Raab, and S. Laborde, "Setting the scientific stage for esports psychology: a systematic review," International Review of Sport and Exercise Psychology, vol. 13, no. 1, pp. 319-352, 2020.

[8] C. J. Walker, "Experiencing flow: Is doing it together better than doing it alone?" The Journal of Positive Psychology, vol. 5, no. 1, pp. 3-11, 2010

[9] C. Harteveld and S. C. Sutherland, "Personalized gaming for motivating social and behavioral science participation." ACM, 2017, p. 31-38.

[10] B. J. Gajadhar, Y. A. W. Kort, and W. A. IJsselsteijn, Shared Fun Is Doubled Fun: Player Enjoyment as a Function of Social Setting. Springer Berlin Heidelberg, 2008, p. 106-117. [Online]. Available: http://dx.doi.org/10.1007/978-3-540-88322-7_11

[11] M. W. Voss, A. F. Kramer, C. Basak, R. S. Prakash, and B. Roberts, "Are expert athletes 'expert'in the cognitive laboratory? a meta-analytic review of cognition and sport expertise," Applied Cognitive Psychology, vol. 24, no. 6, pp. 812-826, 2010.

[12] J. Casanueva and E. Blake, "The effects of group collaboration on presence in a collaborative virtual environment," in Virtual Environments 2000. Springer, 2000, pp. 85-94.

[13] K. Poels, Y. de Kort, and W. IJsselsteijn, D3.3 : Game Experience Questionnaire: development of a self-report measure to assess the psychological impact of digital games. Technische Universiteit Eindhoven, 2007.

[14] W. A. IJsselsteijn, Y. A. de Kort, and K. Poels, "The game experience questionnaire," Eindhoven: Technische Universiteit Eindhoven, vol. 46, no. 1, 2013.

[15] A. Z. Abbasi, D. H. Ting, and H. Hlavacs, "Engagement in games: developing an instrument to measure consumer videogame engagement and its validation," International Journal of Computer Games Technology, vol. 2017, 2017.

[16] A. Z. Abbasi, M. U. Shah, U. Rehman, H. Hlavacs, D. H. Ting, and S. Nisar, "The role of personality factors influencing consumer video game engagement in young adults: A study on generic games," IEEE Access, vol. 9, pp. 17392-17410, 2021.

[17] W. W. Jang and K. K. Byon, "Antecedents and consequence associated with esports gameplay," International Journal of Sports Marketing and Sponsorship, 2019

[18] J. Nakamura and M. Csikszentmihalyi, The concept of flow. Springer, 2014 , p. 239-263.

[19] J. Takatalo, J. Häkkinen, J. Kaistinen, and G. Nyman, Presence, Involvement, and Flow in Digital Games. Springer London, 2010, p. 23-46. [Online]. Available: https://doi.org/10.1007/978-1-84882-963-3_ 3

[20] P. Alavesa, I. Laitalainen, and M. Immonen, "Context defined aspects of gamification for factory floor," in 2019 11th International Conference on Virtual Worlds and Games for Serious Applications (VS-Games). IEEE, 2019, pp. 1-2.

[21] G. Knoblich, S. Butterfill, and N. Sebanz, Psychological research on joint action: theory and data. Elsevier, 2011, vol. 54, p. 59-101.

[22] G. Freeman and D. Y. Wohn, "Understanding esports team formation and coordination," Computer supported cooperative work (CSCW), vol. 28 , no. 1 , pp. $95-126,2019$.

[23] S. A. Jackson and R. C. Eklund, "Assessing flow in physical activity: The flow state scale-2 and dispositional flow scale-2," Journal of Sport and Exercise Psychology, vol. 24, no. 2, pp. 133-150, 2002.

[24] S. A. Jackson and H. W. Marsh, "Development and validation of a scale to measure optimal experience: The flow state scale," Journal of sport and exercise psychology, vol. 18, no. 1, pp. 17-35, 1996.

[25] K. Poels, Y. De Kort, and W. Ijsselsteijn, “"” it is always a lot of fun!" exploring dimensions of digital game experience using focus group methodology," in Proceedings of the 2007 conference on Future Play, 2007, pp. 83-89.

[26] P. Sweetser and P. Wyeth, "Gameflow: a model for evaluating player enjoyment in games," Computers in Entertainment (CIE), vol. 3, no. 3, pp. 3-3, 2005.

[27] H. Zaheer and D. G. Mark, "The attitudes, feelings, and experiences of online gamers: A qualitative analysis," CyberPsychology \& Behavior, vol. 12, no. 6, p. 747-753, 2009.

[28] IBM, "Spss statistics." [Online]. Available: https://www.ibm.com/ support/pages/downloading-ibm-spss-statistics-27

[29] A. Korotin, N. Khromov, A. Stepanov, A. Lange, E. Burnaev, and A. Somov, "Towards understanding of esports athletes' potentialities: The sensing system for data collection and analysis," in 2019 IEEE 
SmartWorld, Ubiquitous Intelligence Computing, Advanced Trusted Computing, Scalable Computing Communications, Cloud Big Data Computing, Internet of People and Smart City Innovation (SmartWorld/SCALCOM/UIC/ATC/CBDCom/IOP/SCI), 2019, pp. 1804-1810.

[30] J. Kim, B. C. Keegan, S. Park, and A. Oh, "The proficiency-congruency dilemma: Virtual team design and performance in multiplayer online games," New York, NY, USA, 2016. [Online]. Available: https://doi.org/10.1145/2858036.2858464

[31] C. Aubé, V. Rousseau, and E. Brunelle, "Flow experience in teams: The role of shared leadership." Journal of occupational health psychology, vol. 23, no. 2, p. 198, 2018.

[32] L. Eklund, "Who are the casual gamers? gender tropes and tokenism in game culture," Social, casual and mobile games: The changing gaming landscape, p. 15-30, 2016.

[33] J. Kinnunen, K. Taskinen, and F. Mäyrä, "Pelaajabarometri 2020: Pelaamista koronan aikaan," 2020.

[34] E. L.-C. Law, F. Brühlmann, and E. D. Mekler, "Systematic review and validation of the game experience questionnaire (geq)-implications for citation and reporting practice," in Proceedings of the 2018 Annual Symposium on Computer-Human Interaction in Play, 2018, pp. 257270

[35] D. Johnson, M. J. Gardner, and R. Perry, "Validation of two game experience scales: The player experience of need satisfaction (pens) and game experience questionnaire (geq)," International Journal of HumanComputer Studies, vol. 118, p. 38-46, Oct 2018. 